\title{
ANGIOCARDIOGRAMS AFTER LIGATION OF THE DUCTUS ARTERIOSUS
}

\author{
BY \\ K. D. KEELE \\ From Ashford Hospital, Staines, Middlesex \\ Received February 16, 1950
}

The diagnostic value of angiocardiography in patent ductus arteriosus has been said to depend on visualization of the small depression in the arch of the descending aorta, and on refilling of the pulmonary artery as described by Steinberg, Grishman, and Sussman in 1943. Since then, some doubt as to the value of this method has been raised; it is, therefore, a test of value to demonstrate the angiocardiographic signs before operation and to note the changes following ligation of the ductus.

\section{CASE NOTES}

The patient was a girl, aged 5 years, who was undersized and mentally backward. There was no history of symptoms referable to the heart.

On examination. No cyanosis. No clubbing. Pulse regular, rate 86. Apex beat just outside the mid-clavicular line. A long typical machinery murmur extending through systole and diastole, maximal in the pulmonary area. Blood pressure, 130/?. Peripheral pulses all easily palpable in arms and legs. No other abnormality on physical examination.

Cardioscopy showed a full-sized heart with ample pulsation. No hilar dance was seen and no prominence in the conus region. The electrocardiogram showed left axis deviation only.

Operation was performed by Mr. Mullard at Hillingdon Hospital. The ductus was found to be short and thick, about $4 \mathrm{~mm}$. in width, and $5 \mathrm{~mm}$. in length. No difficulty in dissection was found, and two thread ligatures were passed and tied; the ductus was not divided. The subsequent course was uneventful and there was no effusion or atelectasis. All cardiac murmurs disappeared.

Angiocardiograms were taken six weeks before and five weeks after operation, and the appearances of these before and after ligation are compared.

\section{Angiocardiograms Before AND AfTER Ligation}

Antero-posterior views. The appearances before ligation, taken 1-2 seconds after injection of $20 \mathrm{ml}$. of 70 per cent diodone are shown in Fig. 1. There is filling of the right auricle and ventricle, the conus of the right ventricle, main pulmonary trunk and both left and right pulmonary arteries. The left pulmonary artery is seen as a rounded shadow superimposed and above that of the main trunk. Particular attention is drawn to the site and shape of this disc-shadow, which is unaltered after ligation of the ductus.

In Fig. 2, taken at 4 seconds, the left auricle is filled. The shadow of the left pulmonary artery has almost disappeared. There is no gross enlargement of the left auricle.

One second later, at 5 seconds, the left pulmonary artery is clearly visualized by a disc-like shadow appearing to the left of the vertebral column over the descending arch of the aorta (Fig. 3A), 


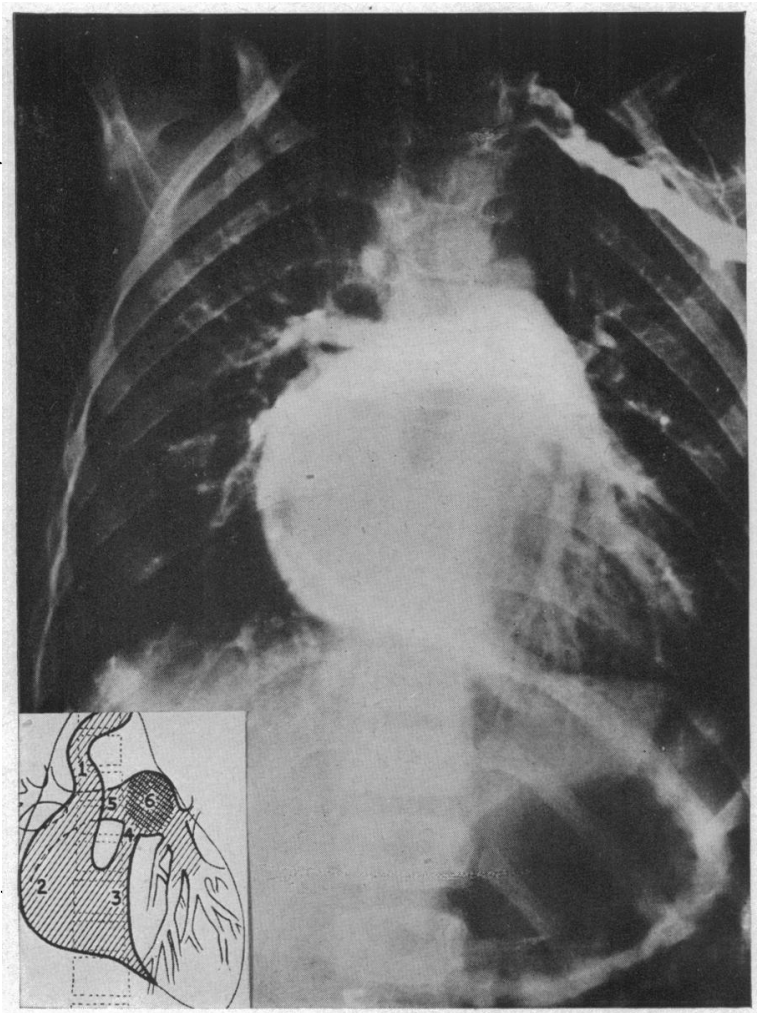

Fig. 1.-Before ligation. At 1-2 seconds. The right side of the heart is filled. Note the disc-like shadow (6) showing the origin of the left pulmonary artery.

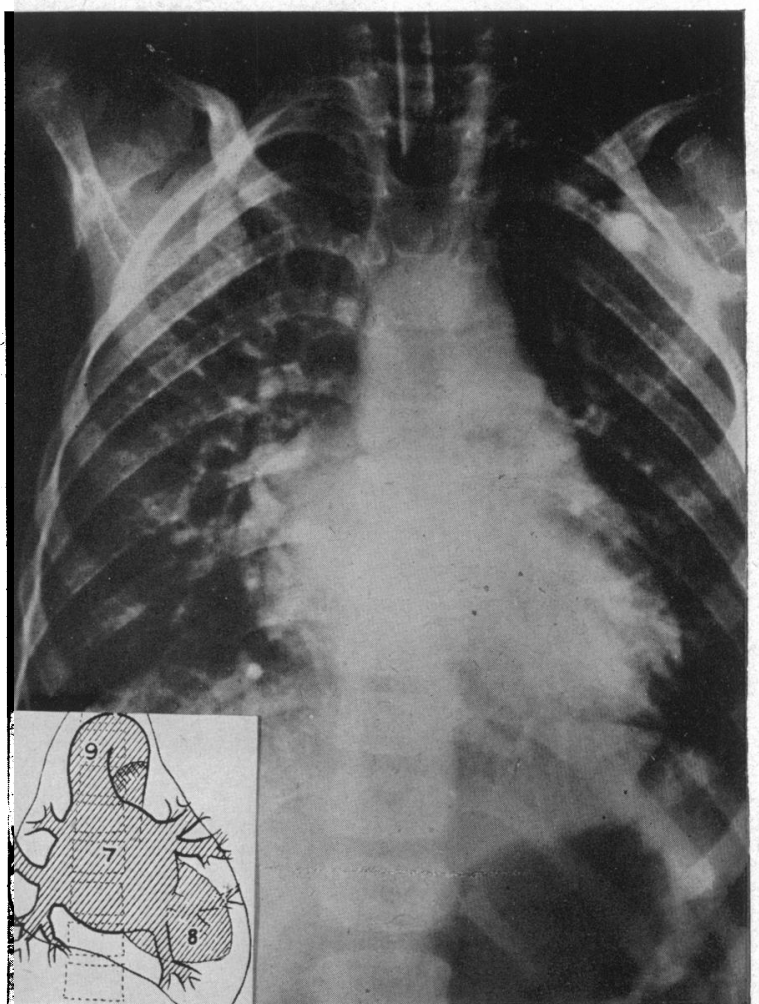

FIG. 2.-Before ligation. At 4 seconds. The left auricle, left ventricle and aorta are filled. The shadow of the left pulmonary artery has almost disappeared.

\section{Key to Diagrams}
1. Superior vena cava.
2. Right auricle.
3. Right ventricle.
4. Main pulmonary artery.
5. Right pulmonary artery.
6. Left pulmonary artery.
7. Left auricle.
8. Left ventricle.
9. Ascending aorta.
10. Descending aorta.

though the rest of the right side of the heart and main pulmonary arteries are now clear. This disc-like shadow corresponds with the left pulmonary artery as shown in Fig. 1.

In Fig. 3B the appearance after operation, at a corresponding time ( 5 seconds), is shown. The arch of the aorta is clearly seen and there is no suggestion of a return of the disc-like shadow in the region of the left pulmonary artery, although the left side of the heart is even better filled. The recurrence of this shadow in Fig. 3A and its absence in Fig. 3B, a corresponding film taken after the ductus has been ligated, shows that it is due to refilling of the left pulmonary artery via a patent ductus arteriosus.

Good visualization of left ventricle and aortic arch was observed in several films over some seconds until the aorta emptied, and there was no return of the disc-like shadow as seen before ligation.

Left Anterior (or Right Posterior) Oblique Views. In Fig. 4A, taken at 5 seconds, before operation, a small eminence of the inner portion of the curve of the arch of the descending aorta is seen with plentiful filling of the pulmonary vessels around, which tend to obscure it. At operation this 


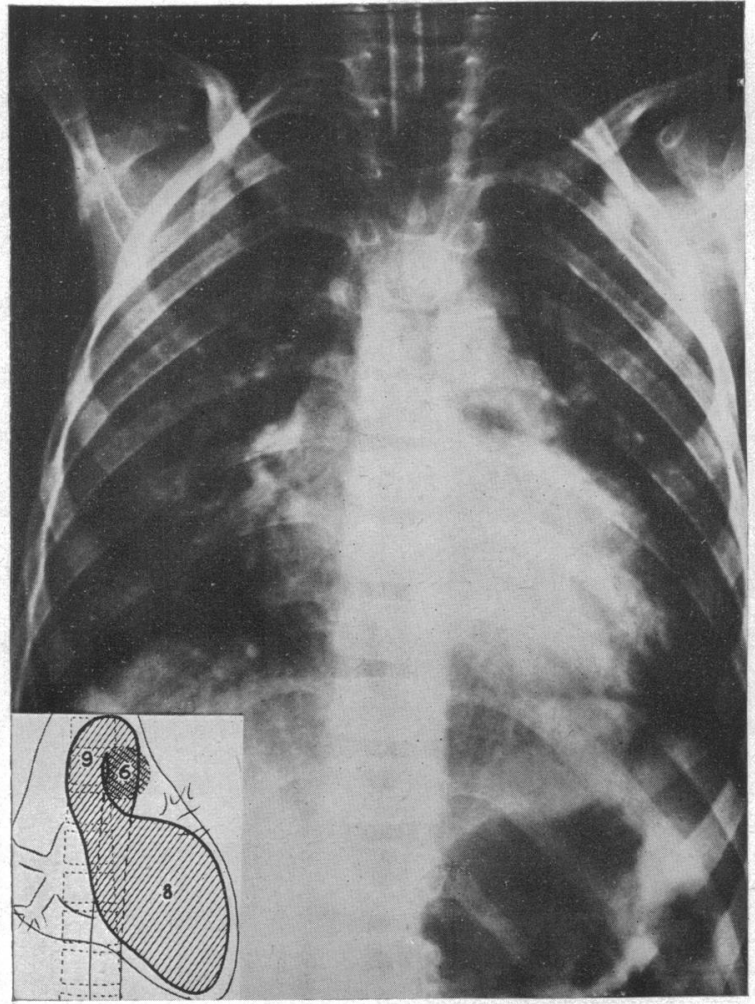

A

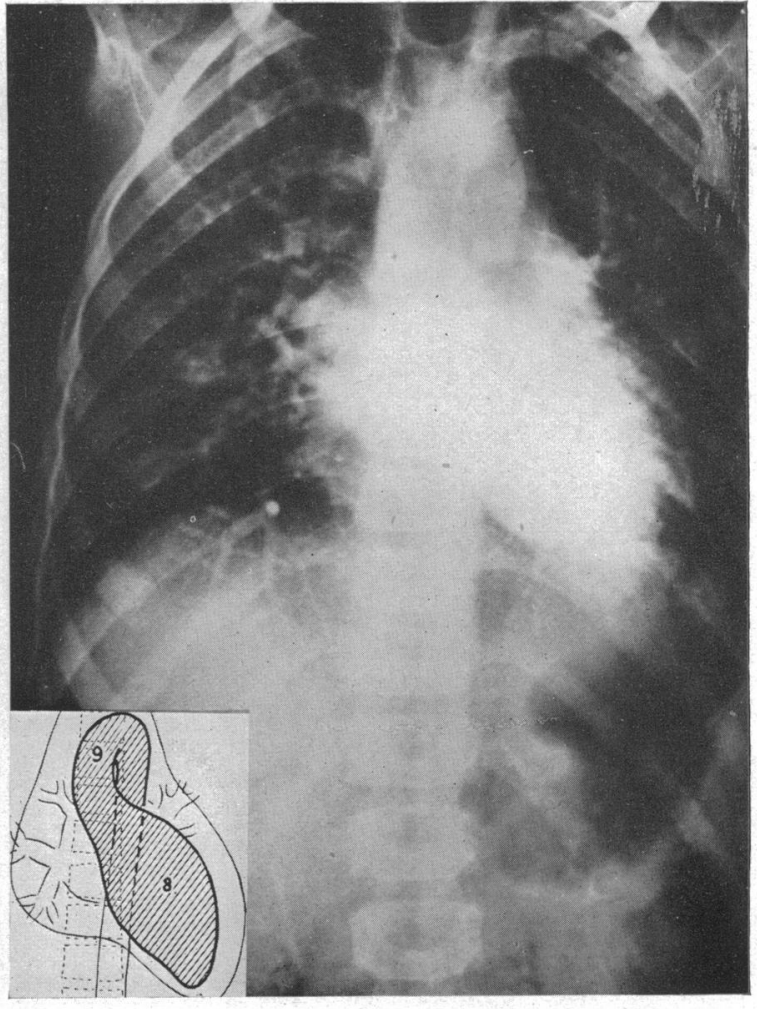

B

Fig. 3.-(A) Before operation. At 5 seconds. The left ventricle and aorta are filled. The disc of the left pulmonary artery (6) appears clearly refilled from the aorta. (B) After operation. At 5 seconds. There is no reappearance of the disc-shaped opacity of the left pulmonary artery at this time as seen before ligation.

eminence or small bulge was clearly demonstrated. After ligation it is seen that this bulge has enlarged (Fig. 4B) and the plentiful opacities of the refilled branches of the left pulmonary artery have disappeared, so displaying the bulge more clearly.

\section{Discussion}

Angiocardiographic diagnosis of patent ductus arteriosus has in the past consisted of visualization of the main pulmonary artery by refilling from the aorta (Steinberg et al., 1943; and Chavez et al., 1947) and the demonstration of a small saucer-shaped dilatation of the aorta at the site of the ductus (Steinberg et al., 1943). Doubt has recently been cast on the value of both these features by the assertion that the site of the arteriovenous shunt refilling the pulmonary artery might be elsewhere than via the ductus, e.g. through a high ventricular septal defect.

It appeared desirable, therefore, to assess the value of angiocardiographic signs by comparing appearances before and after ligation of the patent ductus, as demonstrated here; and the following points regarding angiocardiographic diagnosis emerge.

(1) The sequence of early filling of the left pulmonary artery, followed by emptying, and then refilling at a time when the left ventricle and aorta are filled with opaque medium, presents proof of a communication between aorta and left pulmonary artery which is almost certainly due to a patent ductus arteriosus. This sign has disappeared after ligation, thus proving its relation to patency of the ductus in this instance. 


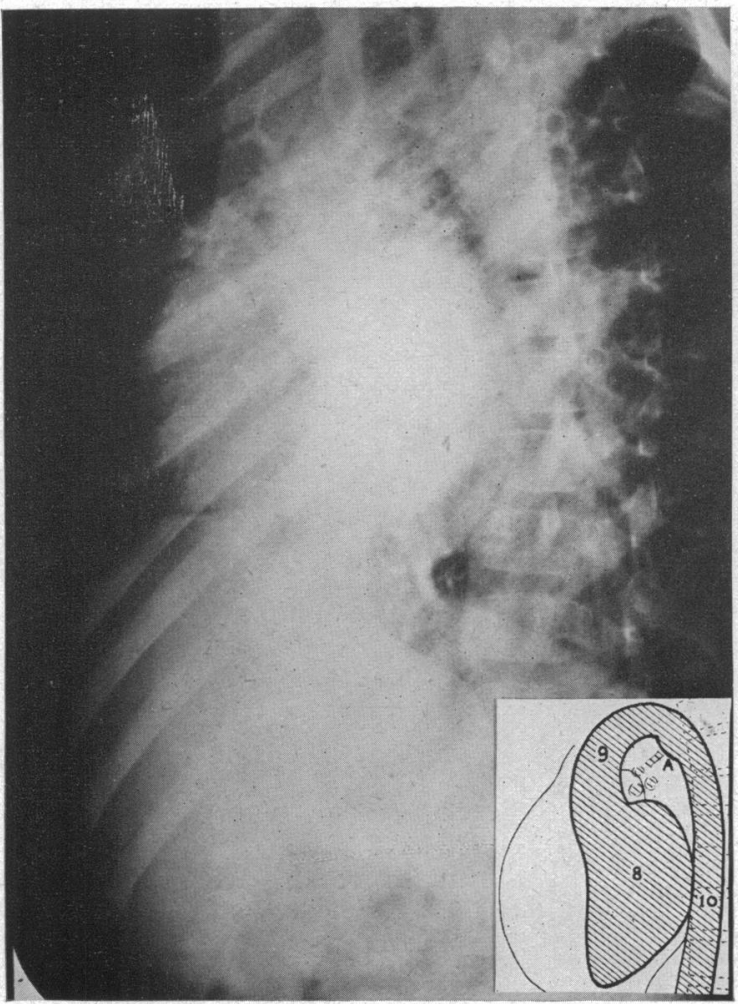

A

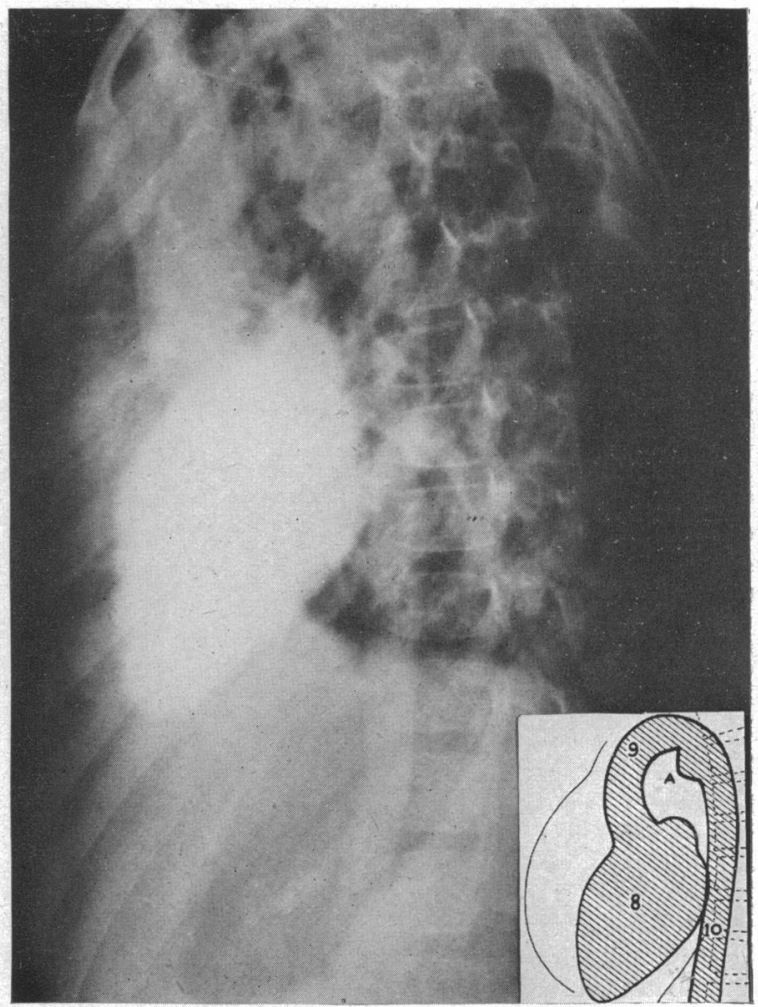

B

FIG. 4.-Left anterior (or right posterior) oblique views. At 5 seconds. (A) Before operation. ' Left ventricle and aorta well filled. There is a slight prominence on the anterior surface of the descending arch of the aorta in the region of the ductus, A. Pumonary vessels are well filled. (B) After operation. The aneurysmal dilatation in the region of the ductus, $\mathrm{A}$, is increased. The pulmonary field is less obscured by opacified pulmonary vessels.

(2) This sequence can only be shown if the bolus technique is used, i.e. a small quantity, $20 \mathrm{ml}$. of diodone rapidly injected so that the right side of the heart is emptied before the left is filled.

(3) The saucer-shaped dilatation of the aorta at the site of the patent ductus is very suggestive, but evidently does not supply diagnostic proof of patency of the ductus, since it was larger and more clearly demonstrated after ligation. Such enlargement has been visualized in 75 per cent of the cases with patent ductus.

The prognosis of the aneurysmal enlargement of the aorta in the region of the ductus after operation deserves consideration. Does this enlarge further? That an aneurysm may form after operation and rupture into a bronchus is shown by two post-ligation cases reported by Jones (1947), in which severe hæmoptyses took place. In one a shadow was seen to appear radiologically in the region of the ductus; in the other exploration two years later showed a 2-ml. cavity in the lung which connected with an open bronchus. Further, that hæmoptysis occurs with an aneurysm of the patent portion of an incompletely closed ductus is exemplified by the case of Hebb (1893) the aneurysm was the size of a walnut and abutted on but did not erode the left bronchus.

There is evidence, therefore, that after ligation of a patent ductus, aneurysmal enlargement at the aortic end may occur. This may encroach on the left bronchus producing hæmoptysis.

\section{SUMMARY}

The angiocardiographic appearances before and after ligation of a patent ductus arteriosus are compared. Emphasis is laid on the disc-like re-appearance of the left pulmonary artery as a 
diagnostic sign, which is obtained more clearly if a small quantity of diodone is used as in the "bolus" technique.

The saucer-shaped enlargement of the aorta in the region of the ductus, though very suggestive of a ductus arteriosus, does not prove patency.

It is a pleasure to acknowledge the help received from Dr. J. A. Brocklebank and Mr. A. Collis of the X-ray Department, Ashford Hospital, in performing these angiocardiograms.

\section{REFERENCES}

Chavez, I., Dorbecker, N., and Celis, A. (1947). Amer. Heart J., 33, 560.

Hebb, R. G. (1893). Trans. Path. Soc., 44, 45.

Jones, J. C. (1947). Thorac. Surg., 16, 306.

Steinberg, M. G., Grishman, A., and Sussman, M. L. (1943). Amer. J. Rontgenol., 50, 306. 